Article

\title{
An Unexpected Means of Embedding Ethics in Organizations: Preliminary Findings from Values-Based Evaluations
}

\author{
Gemma Burford ${ }^{1,2}$, Elona Hoover ${ }^{1,2}$, Lee Stapleton ${ }^{2,3}$ and Marie K. Harder 1,2,* \\ 1 Department of Environmental Science and Engineering, Fudan University, Shanghai 200433, China; \\ G.L.Burford@brighton.ac.uk (G.B.); E.Hoover@brighton.ac.uk (E.H.) \\ 2 School of Computing, Engineering and Mathematics, University of Brighton, Brighton BN2 4GJ, UK; \\ L.Stapleton@sussex.ac.uk \\ 3 Science Policy Research Unit, University of Sussex, Brighton BN1 9SL, UK \\ * Correspondence: M.K.Harder@brighton.ac.uk; Tel.: +44-1273-600-900
}

Academic Editor: Giuseppe Ioppolo

Received: 19 April 2016; Accepted: 27 June 2016; Published: 29 June 2016

\begin{abstract}
Ethical principles constitute a crucial area of debate and discussion in the global conversation around transitions to sustainability, and of particular relevance to the contribution of businesses and other organizations. Scholars in business ethics have recently identified several challenges in this area, such as problems of measurement, rigor, and meaningfulness to practitioners; corporate social responsibility; and institutionalization of ethics in businesses. In this paper, the impacts of a pragmatic values-based evaluation approach originally developed in another field-education for sustainable development-are shown to strongly contribute to many of these challenges. Impacts found across eight organizations include (i) deep values conceptualization; (ii) increased esteem (iii) building capacity for assessment of values-based achievements; (iv) values mainstreaming; and (v) effective external values communications. It seems that the in-situ development and use of values-based indicators helped to conceptualize locally shared values that underpin decisions, thus embedding the application of (local) ethics. Although this study is exploratory, it is clear that the values-based approach shows promise for meeting key challenges in business ethics and wider sustainability, and for new directions for future cross-disciplinary research.
\end{abstract}

Keywords: values-based indicators; business ethics; organizational values; values conceptualization; corporate social responsibility; application of ethics; WeValue; evaluation impact

\section{Introduction}

It is acknowledged that the definition, pursuit and assessment of "sustainability" is not only a technical and political issue, but also a moral and ethical one [1-4]. Ethical values such as compassion, integrity, justice and respect, and ethics-based decision-making, underpin every aspect of sustainability, including several that are not fully encompassed by the traditional threefold definition comprising environmental, social and economic aspects [5,6]. A number of authors propose a "missing pillar" or neglected dimension of sustainability [5-8]. It has variously been characterized as "cultural/aesthetic" [9-12] or with a focus on Indigenous communities [13-15]; "religious/spiritual" [3,4,16]; and "political/institutional" [17,18]. The concept of "ethical values" has been suggested to offer some common ground between these complementary perspectives, and argued as a fourth dimension of sustainability of at least equal importance, inseparable from the others. Difficulties in articulating and measuring the values dimension have been cited as a reason for its neglect, but recent work claims that these can be overcome [5]. 
There have also been a number of high-level calls for the establishment of a global ethical framework for sustainability such as by the Earth Charter $[3,19,20]$, the United Nations Millennium Declaration [21] and the Earth Systems Science Partnership [22]. More recently, the Club of Rome's "ValuesQuest" program, linked to the United Nations Culture, Creativity and Values Initiative, has explicitly sought to embed ethical values as a key concern in international development discourse [23]. Thus, dimensions of values are increasingly being developed in sustainable development.

Organizations and businesses have a central role in the challenge of developing sustainable societies. Already at the turn of the century, Carroll predicted that ethical approaches to business would become a central concern, and emphasized the need for normative approaches to understanding values rather than mere values clarification or "ethical relativism" [24] (p. 41). Over a decade later, mission statements, guiding principles, moral standards and Corporate Social Responsibility (CSR) practices and policies, have become commonplace and core to business activities $[25,26]$ and within them, activities related to values have become increasingly popular [26]. Nevertheless, challenges to the application of ethical values in organizations remain. In 2013, Holland and Albrecht [25] surveyed 3600 members of business ethics societies and networks to identify key future challenges for the academic field of business ethics research. The results included CSR; perceived challenges with legitimacy and credibility of the field; problems of measurement, rigor, and meaningfulness to practitioners; decline of ethical behavior; and the institutionalization of ethics in businesses. We return to these issues later in this paper, but here note the overlap of several current issues in wider sustainable development, such as the actual application of ethical behaviors and developing measures for values dimensions.

In this paper, the authors wish to communicate and explore insights from incidental findings from work in one field—sustainable development—which they show to have potentially significant relevance to current gaps in another field of particular relevance to research in sustainability: business ethics. Evaluation interventions were carried out to assist eight organizations to articulate and evaluate their values and related achievements. Anecdotal feedback suggested that impacts of those interventions included a stronger ability to articulate values and embed these in their organizational practices, and so a follow-up study was carried out to explore this. The authors present findings from that study in this paper.

\subsection{Paradigms in Business Ethics Research}

Prior to presenting the study, the authors outline the context of current research in business ethics. A very useful overview of paradigms present in and across business ethics and organization theory has been published by Pursey et al. [27], charting not only their boundaries and divisions but also the artificial extent of those boundaries, caused by the historical development of various semi-estranged research communities. Although the main intention of that work was to draw out the symbiosis between business ethics and organization theory, a secondary aim was achieved in showing that the pluralism of paradigms and approaches currently present produced a double-edged sword: flexibility and resilience via the range of tools available on the one hand, and a lack of coherence or orientation due to ongoing incompatibilities and even incommensurability on the other hand. The authors illustrated their insights with a multi-faceted presentation of four major themes in the discipline-values, society, power and organizations - from each of modern, symbolic and postmodern viewpoints. Two themes which are of particular interest to us in our own work - values and organizations-were shown to be viewable as individualist or collectivist, almost entirely positivist or constructionist, or anywhere in between, depending on the scholarly community of the researcher. The authors ended with a call to arms for researchers to make greater efforts to engage in science as a social practice and jointly work together across academic "tribes", thus accessing rich sources of new knowledge.

The complex paradigmatic status of the field of business ethics as portrayed by the two studies described above illustrates the difficulties that researchers from other disciplines, such as sustainability, may encounter when trying to communicate concepts and findings which may be of potential interest. 
This is further complicated by the fact that sustainability research itself is characterized by a diversity of paradigms and perspectives [28-30]. One way of negotiating this inherently messy interface, is to focus initially on pragmatic considerations before expanding in the various theoretical domains [31]. Holland and Albrecht—in emphasizing the need for an appropriate blend of academic rigor and practical relevance-lean towards a call for a pragmatist paradigm, stating that sustainability, the decline of ethical behavior and globalization are all candidate issues replete with practical questions of ethics in need of answers [25].

\subsection{Purpose, Paradigm and Context of This Study}

The purpose of this work was to carry out a follow-up study to explore incidental findings of values-based evaluation interventions in eight organizations. The findings of the exploratory study potentially pave the way for new directions in business ethics research in particular, and sustainability more generally, through innovations for firmly embedding values (the fourth pillar of sustainability) into organizations and businesses through the application of localized ethics. They indicate a new way of approaching currently identified research gaps, and allow for scoping out and making recommendations towards specifically designed future studies.

The evaluative interventions of interest were designed as part of a European Union FP7-funded research project to facilitate organizations to evaluate values-related dimensions of their work in a manner that they considered valid and relevant. The project used an emancipatory action research approach, working with organizations and businesses engaged in providing non-formal education for sustainable development (ESD). The latter considered themselves unable to articulate "intangible" aspects of their work which they nonetheless considered key, and the work focused on co-developing an approach that could be highly localized (but also generalized and transferable to some extent) [5,32-35] which later became known as WeValue.

Anecdotal evidence suggested that the WeValue evaluative interventions not only enabled participants to articulate values as individuals and groups, but also led to organizational impacts which far exceeded expectations of researchers or collaborators. Considering the potential importance of effectively bringing values into organizational practices, the authors identified the need for a systematic follow-up study to explore the impacts of the WeValue intervention within a broader organizational context (rather than focusing specifically on project evaluation in relation to non-formal ESD, which has been discussed in depth by Harder et al. [33]). It is the findings of this follow-up study, based on a re-analysis of the original dataset, which we report in this paper. The study is necessarily exploratory as the original project was not purposively designed to explore the impacts, but only to investigate the feasibility of developing and using values-based indicators. However, the re-analysis yields important lessons, as well as much material, for the future design of a systematic study.

The study identified impacts seen in eight organizations, from the time of the intervention up until 3-6 months later, and which included greatly clarified understanding and awareness of shared values, the mainstreaming of those values into work, and a new ability to self-develop ways of capturing "measures" of values-related achievements and communicating them more widely. The depth, scale and consistency of the results were noteworthy. Through increasing our understanding that values awareness is an interpretative process where an individual recognizes moral relevance to their situation [36], and that moral identity is a precursor to ethical considerations [37] we understood that these observed impacts are very relevant to the raising and embedding of ethics considerations into organizations, and to almost every issue identified as a current challenge in business ethics by Holland and Albrecht [25]. Such a focus on values can provide a useful bridge between individuals, organizational culture, practices and behaviors, and indeed be seen as an integral part of organizational culture which provides unconscious guides for tackling complex ethical issues [26].

This exploratory study purposefully follows the call outlined above for research approaches that focus on pragmatic questions. In doing so, the authors examined the impact of the evaluative interventions through detailed case studies, not assuming specific paradigms or theories. However, it is expected that its results will inform future studies designed to test and link those. 
In this paper, we will focus on the impacts of the evaluative interventions, but we will begin with a brief description of the design and content of these interventions. The methodology of the exploratory impact study is then described, followed by the findings. We then present a discussion of the findings in relation to three of the named challenges in current business ethics research-institutionalization of ethics, problems with measurements, rigor and relevance, and CSR — with comments on related other topics.

\subsection{The WeValue Evaluative Intervention: Developing and Using Values-Based Indicators in Organizations}

The WeValue evaluative interventions were carried out in the context of a research project to trial the usefulness and validity of values-based indicators. In this context, it comprised of a number of steps, or variations thereof, delivered in the form of meetings, focus groups, workshops or evaluation activities. The format was not fixed, responding to the different contexts and cultures of each organization, but the core elements are summarized here.

After initial familiarization with the organization and building of rapport, researchers initiated conversations about values in the organization, either with leaders or representative groups. Next, they were asked to look through a selection of values-based proto-indicators previously developed, noting those that resonated with their views on what was important to their own organization. Table 1 lists examples of these proto-indicators, which can be variously associated (or not) with value-labels such as Empowerment, Justice, Respect and Care for the Community of Life, Collaboration in Diversity, Justice, Trust/Trustworthiness and Integrity. Any such associations are locally relevant and not found to be transferable to other organizations, but the proto-indicators themselves were found to be useful and transferable as they were designed to be contextualizable for different organizations. For example, the recurring word "people" can be locally defined as any appropriate stakeholder group, e.g., managers, staff or participants/clients, and could be changed to a more specific term at the users' discretion. The word "entity" typically meant the organization as a whole, but could also be used to refer to a specific department, team, working group, etc.

Table 1. Examples of "trigger" values-based proto-indicators used in Part 1 of the WeValue approach.

Proto-Indicator Examples Taken from the WeValue "Trigger" List

- Decision-making takes into account the social, economic and environmental needs of future generations

- People are able to suspend their own standpoints during dialogue and listen to those of others

- People feel that their own individual identity and approach is respected

- People feel that they have an equal opportunity to express their opinions

- $\quad$ People are perceived to be transparent

- People are taking the opportunity to develop their own visions and goals for projects and/or for the whole entity

- People investigate what is right and good by themselves, rather than adopting other people's opinions

- Partners trust that each shares a commitment and willingness to collaborate for a similar vision

- People feel that they create something better or greater as a group than on their own

- $\quad$ People feel inspired by the way that leaders live their principles

- The environment/community of life is celebrated

During this stage participants usually found articulations of their initial group thoughts on the list, as well as surprising items which represented values they held but which they were previously not very aware of-causing some "Eureka!" moments. The discussions led to clarifications about proto-indicators on the list (values-in-language) and actions in the workplace (values-in-action). After a considerable period of discussion, participants were facilitated to prioritize and sometimes 
cluster the most important proto-indicators to produce their own "list of values-based indicators". This comprised Part 1 of the WeValue approach, which usually had to be separated from Part 2 by at least a few days because the participants often experienced significant clarification of their organizational values, and time was needed for acclimatization: the values-in-action which emerged in the workshops were often newly articulated, or even different to those already formally espoused.

In Part 2 of the WeValue approach, participants were asked which of their own list of values-based proto-indicators they would be interested in developing measures for, depending on their immediate priorities. When identified, the researchers facilitated the participants to co-develop various assessment methods in locally appropriate ways in order to develop "measures" of those proto-indicators that held relevance and validity for the organization. The approach taken was one of co-design and action research, with a strong focus on face-validity. The participants were supported, in effect, to embed ongoing assessments of their own values in their regular activities at levels of rigor appropriate to the purpose required, for example sometimes for self-evaluation and sometimes for external scrutiny. Finally, participants and researchers carried out actual assessments, sometimes few and sometimes many, and with varied levels of participation in the collection and analysis of data. All cases included a follow-up from the research team.

As this paper is focused on the impacts of the WeValue evaluation intervention rather than their content, we do not go into further detail here except to mention two notable points. First, the proto-indicator list was derived from in-depth case studies of five organizations (with multiple sub-projects) and then combined inter-subjectively [38]: the character of that list deserves further research.

Secondly, although the proto-indicators were originally derived from certain values labels such as Trust, Integrity and Unity, such affiliations were not usually found useful or necessary in later work. Organizations often made use of the WeValue approach by instead going directly to the list of proto-indicators. In either case the discussions led to a convergence of agreed values-in-action with specific localized indicators.

More information is available on the origin of the research that produced the WeValue approach-originally designed to help civil society organizations evidence achievements that they felt were undervalued [39]. The action research approach used in its development, which particularly highlighted the importance of localizable proto-indicators, has been reported [34], as have several examples of its use in different organizations as an evaluation approach $[5,32,33]$. None of these report on the impacts of the use of the intervention, or insights of any links with business ethics and current related research gaps.

\section{Methodology}

This paper presents a study of the impacts resulting from field trials of WeValue evaluative interventions conducted by university-based researchers in eight diverse organizations. This represents an exploratory re-analysis of an existing data set collected from the participating organizations at the time of the original funded project. It uses a multiple case study approach [40] based on a qualitative thematic analysis of the original dataset, comprising semi-structured narrative interview transcripts and project documents. The cases analyzed in this study were selected on the basis of having at least two different data sources available for a particular organization, of which at least one was a semi-structured interview. Table 2 provides an overview of all the data sources used in the analysis. 
Table 2. Overview of case study organizations and data sources (all names are pseudonyms).

\begin{tabular}{|c|c|c|}
\hline Organization Pseudonym and Type & Location & Data Sources \\
\hline $\begin{array}{l}\text { "DB": small non-governmental } \\
\text { organization promoting environmental } \\
\text { education and reforestation through } \\
\text { schools and youth groups }\end{array}$ & Mexico & $\begin{array}{l}\text { Two separate face-to-face interviews with Maria, DB director; } \\
\text { Formal written report prepared by Carlos, lead ESDinds } \\
\text { researcher; Meeting minutes and notes }\end{array}$ \\
\hline $\begin{array}{l}\text { "FDJ": secretariat of global umbrella } \\
\text { organization promoting online } \\
\text { sustainability leadership training }\end{array}$ & Costa Rica & $\begin{array}{l}\text { Face-to-face interview with Luisa, project manager responsible } \\
\text { for online training; Formal written report prepared by Luisa }\end{array}$ \\
\hline $\begin{array}{l}\text { "GH": a financial services company } \\
\text { without an explicit commitment to } \\
\text { ethical values }\end{array}$ & Luxembourg & $\begin{array}{l}\text { Skype verbal interview with Philippe, lead ESDinds } \\
\text { researcher; Formal written report prepared by Carlos, assistant } \\
\text { ESDinds researcher; Meeting minutes and notes }\end{array}$ \\
\hline $\begin{array}{l}\text { "HV": a university cross-faculty } \\
\text { environmental program }\end{array}$ & Mexico & $\begin{array}{l}\text { Face-to-face interview with Carlos, ESDinds researcher; } \\
\text { Formal written report prepared by Carlos; Meeting minutes } \\
\text { and notes }\end{array}$ \\
\hline $\begin{array}{l}\text { "JGSD": global umbrella organization } \\
\text { promoting humanitarian aid and } \\
\text { values-based youth programs (through } \\
\text { a federation of national societies) }\end{array}$ & $\begin{array}{c}\text { Switzerland } \\
\text { (secretariat); } \\
\text { Jordan } \\
\text { (summit) }\end{array}$ & $\begin{array}{l}\text { Skype verbal interview and Skype text interview with Rachel, } \\
\text { JMSD project officer in Principles \& Values Department } \\
\text { (re TMSD project); Formal written report prepared by Antonia, } \\
\text { ESDinds researcher (re youth summit) }\end{array}$ \\
\hline $\begin{array}{l}\text { "MJ": a values-driven company } \\
\text { producing and distributing cosmetics }\end{array}$ & Italy & $\begin{array}{l}\text { Face-to-face interview with Stefan, ESDinds researcher; } \\
\text { Meeting minutes and notes }\end{array}$ \\
\hline $\begin{array}{l}\text { "QU": small non-governmental } \\
\text { organization training youth to promote } \\
\text { conflict resolution in schools through } \\
\text { forum theatre }\end{array}$ & Germany & $\begin{array}{l}\text { Face-to-face interview with Josef, QU director; Skype voice } \\
\text { call with Ingrid, project manager; Formal written report } \\
\text { prepared by Stefan and Karina, ESDinds researchers; Meeting } \\
\text { minutes and notes }\end{array}$ \\
\hline $\begin{array}{l}\text { "TMSD", a member organization of } \\
\text { "JGSD" that provides humanitarian } \\
\text { activities and projects for } \\
\text { conflict-affected youth }\end{array}$ & Sierra Leone & $\begin{array}{l}\text { Skype verbal interview and Skype text interview with Ibrahim, } \\
\text { project manager; Face-to-face interviews with Carlos and } \\
\text { Stefan, ESDinds researchers; Formal written report prepared } \\
\text { by Carlos and Stefan; Meeting minutes and notes }\end{array}$ \\
\hline
\end{tabular}

\subsection{Collection and Preliminary Analysis of the Original Data Set}

The data set from the original ESDinds project included (a) researchers' formal project reports and field notes; (b) transcripts of semi-structured narrative interviews with key informants-organization directors, project managers, or both, as practicable-in participating organizations; and (c) transcripts of interviews with the researchers who conducted the field visits and evaluative interventions. All of the interviews lasted 60-90 min and were conducted 3-6 months after the field visits, with a view to clarifying both processes and outcomes of the interventions. The selection of interviewees was made on a convenience sampling basis within those organizations which, at the time of the original study, had already completed the WeValue evaluative intervention. Standard ethical procedures for prior informed consent and secure data storage were observed. The interviewers aimed to elicit narratives of processes and outcomes during the field visits in participants' own words, without priming for values conceptualization or "benefits", to avoid compromising validity by imposing preconceptions of what the outcomes might be. This dataset had previously been analyzed at a relatively superficial level, firstly to meet reporting requirements for project donors [41], and secondly in relation to literature on the uses and influence of evaluation.

\subsection{Thematic Analysis Methodology}

A thematic analysis was carried out in order to identify predominant themes relating to the longer term outcomes of the WeValue evaluative intervention. The full dataset was analyzed using "parallel coding", i.e., first coded separately by two authors, and then discussed in joint meetings to develop consensus and finalize themes. The researchers used the computer-aided qualitative data analysis software (CAQDAS) program Atlas.Ti. After the themes were finalized, the researchers conducted a content analysis for each of the themes, to identify more precisely the occurrence of related impacts and outcomes. 
The thematic analysis was completed using both open and a priori codes; the latter were taken from literature on values, semiotics and inter-subjectivity (cf. [37]). This was consistent with the research approach adopted, as pragmatists seeking "a good trade-off between theoretical inspiration and openness toward empirical material" in common with Alvesson and Sveningsson [42] (p. 968). The researchers also characterized the findings in terms of their impact relating to managers, staff, or clients involved in the evaluative intervention (cf. Agle and Caldwell [43]). The authors opted not to fully quantify the data, due to concerns that listing the number of case studies in which each outcome was observed might mislead readers into inappropriately ranking outcomes in order of importance on the basis of frequency alone (see Table 3).

Table 3. Themes relating to the impact of the WeValue evaluative intervention, and an overview of the strength of evidence found for each. A single tick designates outcomes observed in only one organization; a double tick in two or more. A question mark indicates outcomes that the authors regarded as likely, but were not demonstrable from the data.

\begin{tabular}{|c|c|c|c|}
\hline Themes & Managers & Staff & Beneficiaries/Clients \\
\hline \multicolumn{4}{|l|}{ Values Conceptualization } \\
\hline Adding referents to value-labels & $\sqrt{ } \sqrt{ }$ & $\sqrt{ } \sqrt{ }$ & $\sqrt{ }$ \\
\hline Adding value-labels to referents & $\sqrt{ } \sqrt{ }$ & $\sqrt{ } \sqrt{ }$ & $?$ \\
\hline General understanding and acceptance of values & $\sqrt{ } \sqrt{ }$ & $\sqrt{ } \sqrt{ }$ & $\sqrt{ } \sqrt{ }$ \\
\hline \multicolumn{4}{|l|}{ Esteem-Related Outcomes } \\
\hline Increased self-esteem/self-awareness & $\sqrt{ }$ & $?$ & $\sqrt{ } \sqrt{ }$ \\
\hline Increased understanding and acceptance of others & $\sqrt{ } \sqrt{ }$ & $\sqrt{ } \sqrt{ }$ & $?$ \\
\hline Increased understanding of the organization as a whole & $\sqrt{ } \sqrt{ }$ & $\sqrt{ } \sqrt{ }$ & $\sqrt{ }$ \\
\hline Increased understanding of wider human-environment system(s) & $?$ & $\sqrt{ }$ & $?$ \\
\hline \multicolumn{4}{|l|}{ Assessment Capacity Building } \\
\hline Increased understanding and acceptance of indicators & $\sqrt{ } \sqrt{ }$ & $\sqrt{ } \sqrt{ }$ & $\sqrt{ } \sqrt{ }$ \\
\hline Increased understanding and acceptance of assessment methods & $\sqrt{ } \sqrt{ }$ & $\sqrt{ } \sqrt{ }$ & $\sqrt{ }$ \\
\hline \multicolumn{4}{|l|}{ Internal Transformation/Values Mainstreaming } \\
\hline Personal commitment (“buy-in") to organization's activities & $\sqrt{ } \sqrt{ }$ & $\sqrt{ } \sqrt{ }$ & $\sqrt{ } \sqrt{ }$ \\
\hline Individual behavior and/or group dynamics & $\sqrt{ }$ & $\sqrt{ }$ & $\sqrt{ } \sqrt{ }$ \\
\hline \multicolumn{4}{|l|}{ Values mainstreaming within the arena of: } \\
\hline Strategic planning processes & $\sqrt{ } \sqrt{ }$ & $\sqrt{ }$ & $\sqrt{ }$ \\
\hline Training and internal communications & $\sqrt{ } \sqrt{ }$ & $\sqrt{ }$ & $\sqrt{ }$ \\
\hline Individual performance assessment & $\sqrt{ } \sqrt{ }$ & $\sqrt{ }$ & $\sqrt{ }$ \\
\hline Organizational performance assessment & $\sqrt{ } \sqrt{ }$ & $\sqrt{ }$ & $\sqrt{ }$ \\
\hline \multicolumn{4}{|l|}{ External Communications } \\
\hline To donor organizations & $\sqrt{ }$ & $?$ & $\sqrt{ }$ \\
\hline To existing partners or clients & $\sqrt{ } \sqrt{ }$ & $\sqrt{ }$ & $?$ \\
\hline To prospective partners or clients & $\sqrt{ }$ & $?$ & $\sqrt{ }$ \\
\hline To policy-makers & $\sqrt{ }$ & $?$ & $?$ \\
\hline
\end{tabular}

\section{Findings}

Five main impact themes were developed from the analysis, namely (i) values conceptualization; (ii) esteem raising (raised awareness and value of identity at individual and group levels); (iii) values mainstreaming/internal transformation impacts; (iv) values-based assessment capacity-building; and (v) external communications impacts.

A summary of their relative occurrence at different levels (managers, staff and clients) is shown in Table 3, and illustrative quotations are given for each in the sections below and in Table 4. 
Table 4. A summary of illustrative quotations for each theme.

Theme Sub-Themes

Values

conceptualization

\section{Illustrative Quotations}

"... all participants stated that their consciousness of the presence and importance of values had been greatly heightened, and that after the field visit they tend to look in terms of values at their work and interactions, both individually and organizationally, in a new way." [44]

"...in a region full of sexism, where women do not have that access (to information and decision-making) generally, the youth realized that the project has generated a space of equity. However, that (the WeValue approach evaluation) was the moment when they became aware of it ... With the youth, I had been working consciously, very much, around providing that equity, but I never gave them a logo about it: I never said "this is about equity", I just created it." [45]

"I think [the youth] got a better understanding of what it is to be involved in (the JGSD global initiative) and that values are the foundations of this movement ... It gives them a global picture and a deeper understanding of how you can put into action those values." [46]

"Only four JGSD Fundamental Principles were cited by the trainers: humanity (11 times), unity ( 3 times), independence (1 time) and service (1 time)—compared to respect, which was cited 43 times. This suggests that identifying values is very subjective, but also that the process of identifying values from indicators (more tangible expressions of those values), draws out values that are based on experience rather than ones based on more abstract concepts." [47]

"With respect to the youth, they said it in public, that after this process they understand one another better and they value much more what they're doing. They've always felt very united, but now they know why they're united." [48]

"Through the processes and assessment tools, we (managers) were able to get a deeper insight into the young people's sense of self, each other and the community. The biggest help for me was an added insight into their motivation, awareness and

Increased understanding and consciousness of themselves and others, and the connection with the group and the environment." [45]

Esteem-related acceptance of self, others,

outcomes
a whole (all inter-related)

"Professor S. stated that she had observed positive attitudinal changes as a result of the field visit in all participating staff and volunteers and in her own self, in a way she felt was deeply rooted and transformational."[44]

"It was really, really encouraging. (The youth) can see the things that they still have to work on. In addition, then in some places, we could say to them, "There is this gap between you and us (i.e., managers); what can we do about it?" It felt really good. I was the one who led the conversation. It was positive, I really enjoyed it. They became more self-confident." [49]

"I would say that this has affected them positively in terms of respect for leadership, now they realize that those leaders were not imposing something or showing that they wouldn't improve, but they were the spokesmen or spokeswomen much more." [50]

"(At a national youth camp, the youth group members) ran the same process for other youth. They offered it as an ice-breaker

Assessment

ncreased understanding and acceptance of indicators and activity. They did a spiral of "where are you?"(i.e., spatial survey using a spiral)—-they chose four indicator questions and asked them, using the spiral." [45]

capacity building acceptance of indicaters aled)

"They simply liked the assessment tool, and they want to be able to replicate it on their own, so they taped it on a video ... " [51] 
Table 4. Cont

Theme

Sub-Themes

Personal commitment (buy-in)

group dynamics

Internal transformation

values

mainstreaming

Strategic planning

Training

Individual behavior and
group dynamics

they should be, what they should be doing in the changing their mindsets, especially with these Principles and Values of JGSD ... making a difference within their own communities with their own actions. They seem more mature." [46]

“The original indicator was 'Group norms exist and they are followed.' For that question everybody went into (the part of the piral that represented the answer) 'More or less'. We asked them, 'Why? You make your own rules, and there is no pressure or imposition of these norms, why don't you respect them?' And as a result of that process the youth made a commitment (to respect them), without me putting any pressure on them, but because they felt ashamed. They promised to follow the norms like arriving on time and keeping the blog updated. It has worked, I am here and they are doing everything! That result transformed the group relationship."[45]

"As a result of this process we decided that next year we would not do as many activities but we would identify those with the highest impact on selves, communities and ecosystem, thanks to the information provided by the indicators. It helped us to prioritize our activities, we had such a broad spread of action." [45]

"One of the peer educators said that previously, in presenting the Earth Charter in the workshops she used to focus on concrete

behaviors, such as recycling waste. Following the field visit she stated that she now puts a much greater emphasis on the Earth Charter values, and sees the Earth Charter not just as a way of achieving specific behaviors but in terms of the development of the whole individual, beginning with herself, and for participants also ..." "[44]

"After (the field visit) we changed our preparation phase (for new volunteers) to values. The first week we focused on service, the second week on consultation, the third on being an example, the fourth on consultation, and the fifth on unity ... Before when we did the preparation phase, we just focused on themes, like acting, etc., and each week we would look at a topic connected to [the organization] and the show." [49]

Internal communication
"We could see where there were differences between the youth and the staff, especially about information, we could see where the
youth especially see that there are difficulties with communication between them and the staff." [49]
"I realized that before I was categorizing (schools) according to more superficial aspects, and what was missing was the values.
That made me realize that we have to impart the value of Respect and Care for the Community of Life right at the start... if that
acquired a clearer lens since the visit." [45]

Individual performance assessment acquired a clearer lens since the visit." [45]

“(Our previous approach to individual performance assessment) was just my own intuition as a teacher, but without any certitude...I could see values there in the relationships and the commitment, but I couldn't see how it was possible to measure. (In the WeValue approach process) through dialogue, we were gradually arriving at the complexities and translating it into something marvelously simple that gave deep information." [45]

Organizational performance assessment 
Table 4. Cont.

\begin{tabular}{|c|c|c|}
\hline Theme & Sub-Themes & Illustrative Quotations \\
\hline \multirow{5}{*}{$\begin{array}{c}\text { External } \\
\text { dissemination }\end{array}$} & Donors & $\begin{array}{l}\text { "Thanks to this process, (our major donor) has re-conceptualized the work of DB as something of international relevance, no } \\
\text { longer just a local project." [45] } \\
\text { "(DB's major donor) was very interested. They asked me if I would be interested in developing an entire indicator system for their } \\
\text { national work, tailor-made, as opposed to the generic WeValue one." [52] }\end{array}$ \\
\hline & Existing partners/clients & $\begin{array}{l}\text { "In the schools it worked, the process was very helpful, in particular helping the teachers and the headmasters to understand that } \\
\text { my work is not just teaching the children how to plant trees, but also in values. It helped in the relationships with the institutions. } \\
\text { The schools saw that we were creating respect for the community of life." [45] }\end{array}$ \\
\hline & Prospective partners/clients & $\begin{array}{l}\text { "It would make it easier for new schools who think about working with us. It's sometimes hard for us to explain what goes on in } \\
\text { our performances. We normally have to give them a live example, show them a full performance so that they can see an example } \\
\text { of what we do, and then they decide. It works, but it's very time-consuming. If we can measure values, we can give them more } \\
\text { clarity." [53] }\end{array}$ \\
\hline & \multirow[t]{2}{*}{ Policy-makers } & $\begin{array}{l}\text { "We nearly had a couple of meetings with the President. We did have a meeting with the Minister for Education and Youth who } \\
\text { had a behavior change program which the President is very close to. They were very interested in the WeValue approach. That } \\
\text { was also part of what helped the process of assimilation. Because at that meeting it wasn't just us presenting it, but also (local } \\
\text { managers), particularly 'Ibrahim", presenting the WeValue approach as he understood it to the government, in terms of the } \\
\text { relevance that he felt." [54] }\end{array}$ \\
\hline & & $\begin{array}{l}\text { "... since we met our national secretariat here and we spoke about these values indicators and the measurement of these values } \\
\text { indicators, and (in) their own jargon now, every time they come on to the media that's all that they're talking about." [55] }\end{array}$ \\
\hline
\end{tabular}




\subsection{Values Conceptualization}

Very strong evidence of values conceptualization was found in all eight organizations studied, (i.e., creating or enhancing experiential understandings of "values"). This occurred through strengthening of the links between values-in-language (such as named values-labels like Trust, or specific values-based indicators such as those in Table 2) and values-in-action. This occurred in three slightly different mechanisms: (a) starting with the value-labels and then adding "referents"—-statements about how those values would be enacted in practice within the given context; (b) starting with the "trigger" proto-indicator(s) and then identifying relevant "values-label" words or related phrases; and (c) by starting with proto-indicators in language and relating them to values-in-action without use of any values-labels in the process.

Whichever values items were used, by reflecting on them individually and then discussing, exploring, debating and modifying the details of them collectively, participants achieved a deeper and richer shared understanding of how these espoused values were (or could be) enacted within their organizations. The data revealed that they took this new perspective with them in the following months:

"... all participants stated that their consciousness of the presence and importance of values had been greatly heightened, and that after the field visit they tend to look in terms of values at their work and interactions, both individually and organizationally, in a new way." [44]

In some cases the values-based indicators which were discussed and refined were similar to the values espoused in pre-existing documents such as mission statements and websites, but in other cases they were very different interpretations or even entirely new "core values" that had not previously been acknowledged or discussed. Several examples were seen of underlying values which were key to group work—but previously unarticulated—being elicited and then verbalized:

“...in a region full of sexism, where women do not have that access (to information and decision-making) generally, the youth realized that the project has generated a space of equity. But that (the WeValue evaluative intervention) was the moment when they became aware of it ... With the youth, I had been working consciously, very much, around providing that equity, but I never gave them a logo about it: I never said 'this is about equity', I just created it." [45]

Beyond the distinct processes discussed above, namely the addition of referents to specific value-labels and vice-versa, we also found evidence for a broader, slower and "fuzzier" values conceptualization and awareness-raising effect arising from the WeValue intervention. This seemed to begin with an enhanced general awareness that values did indeed underlie day-to-day actions within the organization, moving to a realization that they could be made visible through values-based evaluation, and thus to a reinforcement that values provided a useful and relevant framework with which to view their work:

"I think (the youth) got a better understanding of what it is to be involved in (the JGSD global initiative) and that values are the foundations of this movement ... It gives them a global picture and a deeper understanding of how you can put into action those values." [46]

Although assessment capacity is mentioned below as a separate impact category, it is worth noting the finding that when the organizations performed assessments of their values-based indicators and then had before them "measures" indicating the extent of their presence, that this had a visible reinforcement effect in some cases. The quote about "equity" above is an example: assessment results reinforced that it was present and reminded participants of its importance to them. Thus, assessment reinforced values conceptualization and awareness-raising. 


\subsection{Esteem-Related Outcomes}

The WeValue evaluative interventions contributed to deepening people's understanding, acceptance and valuing of themselves, one another, and the group or organization. These ranged from improvements in the self-esteem of individual managers or employees, through changes in the way in which managers understand and value their staff (or vice-versa), to new understandings of the significance of the organization's work (see Tables 3 and 4 for details). The distinction between general values conceptualization and these esteem-related outcomes may not always be entirely clear. However, we see the former more as the development of a values-based lens with many components, whereas the latter are consequences, e.g., new ways of viewing colleagues and work through that new lens:

"This project helped us a lot and it still helps. We try to think about what is the value behind (participants' actions) ... This is how we see each human being, full of values." [49]

Some interviewees also commented explicitly, and others implied, that these outcomes have a strong morale-boosting effect. Thus, reflection on one positive outcome could generate others. In one case an organization (DB) was inspired by Indigenous environmental values and the director alleged that the intervention had changed not only the participants' view of their own organization but also their understanding and awareness of the human-environment system within their forest [45]. Our qualitative data contain several examples of improved relationships between managers and staff, improved self-esteem, and specifically "feeling understood and valued".

\subsection{Assessment Capacity Building}

In the second part of the intervention (Part 2), participants were facilitated to understand and develop assessment tools to produce "measures" of the indicators they had prioritized. In many cases, assessment tools were designed to fit in closely with the day-to-day activities of the organizations. The degree of rigor and type of validity required was discussed and varied depending on the specific needs. Table A1 (Appendix A) shows those used for one organization, including observations, surveys, key informant interviews and theatrical performance. Some indicators had only single, informal measures for one aspect, while others had several assessments, designed to provide a more rigorous evaluation. It was not expected, from the initial intervention, that the organizations would make a sustained use of the assessment methods developed, or be able to go further and develop new ones in the future.

Our findings showed that, several months later, a number of organizations had continued to use —and, in a few cases, even to extend - the assessment methods. It seems that the WeValue evaluative intervention can be useful for building capacity in performance assessment. Managers and their staff (and, potentially, clients) can learn new ways of understanding and evaluating the work of individuals and of the whole organization: in ways which resonate with them and instill a feeling of ownership. Some of the organizations' managers, staff and even clients acquired new understandings of the concept and uses of indicators, and of specific assessment methods (See Table 4 for illustrations). In two cases, DB and TMSD, managers and clients were empowered to use the WeValue evaluative approach independently in different contexts $[45,55]$. As these were non-profit groups that were not previously comfortable with performance assessment, beyond their formal donor-driven evaluations, this was a significant and unexpected outcome.

The experience of the WeValue evaluative intervention inspired organizations accustomed to quantitative evaluation to explore qualitative and creative ways of understanding impact. Conversely, small organizations who have avoided formal evaluation found the WeValue evaluative approach an attractive alternative which encouraged them to adopt systematic surveys and observations.

As previously mentioned, assessment of tangible "measures" of values concepts in the organization inevitably reinforced their meaning to participants, embedding the shared values. 
Although not seen in these eight examples, this also opens the possibility of reinforcing dissonance in groups where the "shared values" are not shared by all participants.

\subsection{Values Mainstreaming and Internal Transformation}

Considering the existence of the findings discussed above of values conceptualization and awareness raising, increased value of self and others, and increased ability to determine measures of values in everyday activities, it is perhaps not surprising that the authors also found evidence of the joint impact of those into a higher-level impact of values mainstreaming, i.e., the shifting of the organization to a more "values-based management" approach. Evidence was found of observable changes in the following arenas: assessment of individual and/or organizational performance; strategic planning; internal communications; and training protocols.

Internal transformation, while encompassing all of the above, is a broader category that can also include changes in "buy-in" or commitment to the organization and its activities, as well as changes in individual behavior and group dynamics-not necessarily directly values-based. Increased buy-in, changes to strategic planning processes, improvements in individual behavior and group dynamics, and changes to training, assessment and internal communications protocols were all observed at the managerial level in more than one case study. At the staff level, increased buy-in was observed in several cases, and each of the other named outcomes was evident in one case study. Among participants/clients (e.g., beneficiary youth groups), both "increased buy-in" and "changes in individual behavior and group dynamics" were observed in more than one case study, and each of the other outcomes in one case study. Specific examples of all these impacts are given in Table 4.

It is possible that by illuminating "value-action gaps", the WeValue approach may serve as a catalyst for self-directed individual behavior change without the need for authoritarian managerial intervention, a theme that the authors will explore further in future work (and for which we welcome collaboration).

Of particular interest is the example of concrete behavior change cited in organization $\mathrm{DB}$, where the members of the youth group recognized through the participatory evaluation that they were failing to meet their own self-imposed norms. As a result, and without any direct intervention from their manager, they changed their behavior in order to conform more fully to the standards that they had set themselves. This, in turn, transformed the group dynamics.

\subsection{External Communications}

As might be expected from transformational work on organizational values, important subsequent external communication activities took place between organization managers and their counterparts in partner organizations, such as the head teachers of schools participating in an environmental project. There were also significant and intriguing single-case examples of new styles of communication to donors and policy-makers in organizations DB and TMSD respectively $[45,54]$. Table 4 provides illustrative examples from the data. The interview data hint at secondary outcomes occurring within these recipient organizations and institutions, which in turn have gone on to adopt value-labels and the WeValue approach referents into their own vocabularies. The major donor to DB has since commissioned a large multi-level evaluation of its own national programs using the WeValue approach [37].

The data shows that new understandings generated through the WeValue approach can catalyze change within the organization in question, and also transform the way in which the organization presents itself to others.

\section{Discussion}

The findings detailed above clearly illustrate how the WeValue evaluative interventions helped organizations respond to a number of key issues identified in business ethics research. Some of the challenges mentioned by Holland and Albrecht [25] are directly addressed, such as problems of measurement, rigor, and meaningfulness to practitioners; the institutionalization of ethics in businesses; 
and CSR. We first discuss the linkages to these named challenges, and then consider linkages to some conversations in the wider business ethics literature.

\subsection{Problems of Measurement, Rigor, and Meaningfulness to Practitioners}

Fundamental to the usefulness of the WeValue approach is its ability to efficiently facilitate participants to articulate in discourse what they already undertake or experience together as values-in-action. In that way, they jointly develop values-based indicators-short sentences that clarify a manifestation of a shared value. This process helps to concretize values that underpin decisions about what is or is not ethical. Once produced, the same indicators effectively provided criteria for the practice and application of ethics-which can also be used to devise informal or formal "measures" that are valid to the participants and adapted to the context (see Appendix A). Organizations that had previously eschewed evaluation methods of any kind, enthusiastically developed localized assessment methods to provide "measures" of these indicators which then informed observable practices of individuals and groups-precisely because they considered the indicators very meaningful to them and the measures a mechanism for self-evaluation and learning. The levels of rigor used depended on the purpose: in some cases three assessment methods were used for one sole indicator, which itself might be only one of a set of 10-12 indicators designated-locally, by that organization-to be elements of one core value. The measures developed for those twelve indicators could then provide a meaningful and rigorous representation of that core value to members of the organization, their stakeholders or funders. In other cases, participants used a simple measure of fewer indicators, giving more importance to the localized statement itself rather than an overarching label. Regardless, the purposefully designed localizability of indicators, and flexibility in choice and design of assessment methods, provided local solutions to these challenges for the practitioners involved in these eight organizations. This process does not exclude external evaluations: external evaluators could be allowed to specify other indicators from the locally derived pool, or still use their own.

\subsection{Institutionalization of Ethics}

The institutionalization of ethics in organizations as described by experts in the field of business ethics broadly refers to developing strong ethical cultures and a clear focus on how to apply ethics in all practices of the organization. The findings from this exploratory study suggest that clearly conceptualizing shared organizational values-through meaningful discussion-and developing concrete indicators to effectively define them in practice, led to mainstreaming of values in the organization. The fact that the indicators were designed to be operationalizable, and that the participants co-developed specific assessment tools for the values-based indicators may be key: they might have effectively integrated different ways of understanding ethical values in everyday practices. The contextually developed values-based indicators became reference items, not only for possible evaluation, but also for guiding ethical judgments during decision-making processes. Furthermore, the participatory nature of the WeValue evaluative intervention, which included deep discussions leading to the conceptualization of shared values, and involvement in the evaluative process, gave space for reflection on developments in the organizations' ethical culture. An example of this was the youth group in organization DB which realized it was not conforming to its own agreed group norm of punctuality, and changed their behavior-without managerial intervention. The director of the same organization reported presenting their work differently to funders after embedding the new indicators in their work: no longer as an organization focused on reforestation alone, but on reinforcing values such as empowerment, equity, and the emotional connection to the wider community of life.

\subsection{Corporate Social Responsibility}

The values conceptualization, mainstreaming and external communication impacts of the WeValue approach outlined above have important implications for the understanding and application of CSR in organizations. The indicators approach allowed for the conceptualization and operationalization of the organization's values, in turn providing clear guidance for managers, staff and beneficiaries on 
the actual practices that support CSR within the organization and helping to move "from rhetoric on business ethics and CSR to meaningful action" [25] (p. 783). In addition, the values-based indicators and their measures provide potential for generating measures of ethics and CSR practices, and can provide innovative and meaningful ways of communicating such practices.

Values conceptualization and mainstreaming can generate diverse examples of a company's commitment to values-and provide conceptual and strategic frameworks for reporting CSR. This is a valuable tool for companies faced with an increasingly cynical public wanting evidence of the triple bottom line [56] and critical of empty values statements not backed up by action [57]. Indeed, while $64 \%$ of the 250 largest multinational companies published Corporate Social Responsibility (CSR) reports in 2005, the majority of them listed multiple uncoordinated initiatives rather than elucidating a coherent strategy [58]. The WeValue approach thus appears capable of providing a values-based strategy, and clear indicators for internal and external communication, monitoring and evaluation.

\subsection{Linkages to Wider Conversations on Values in Organizations}

Although a relatively new focus in sustainability research, the concept of values has long been central for conversations business ethics, management and organization studies. We show here some linkages of the impacts of the WeValue approach to some of them.

In an effort to study the challenge of applying ethics in practice, a number of researchers have focused on behavioral ethics approaches, investigating the influence of values held by individuals within an organization, with evidence that these can influence employee behavior and decision-making processes. Values have been described as a key element of exemplary leadership [59], a way for managers to influence individual behavior without resorting to authoritarianism [60], and an important mediator in decisions about equal resource allocation [61]. Enhanced values focus in management has also been shown to increase trust and understanding between managers and their subordinates $[62,63]$.

This is in contrast to approaches in organization studies, which focus on values at the organizational level. Such research provides evidence for the influence of collective values-and how these are perceived-on those working within organizations. In their study of 902 managers from different contexts, Huhtala et al. [64] demonstrate that there is a positive relationship between managers' perceptions of ethical organizational culture and occupational well-being. Other studies have demonstrated the positive effects of congruence between individual and organizational values on staff retention, satisfaction and increased ethical behavior $[65,66]$. Indeed, values can be seen as an integral part of organizational culture that provide unconscious guides for tackling complex ethical issues [26].

The WeValue approach provides some insights to these studies, and links between them. For example, the impact findings show how collective conceptualization and later evaluation of values-based achievements has effectively united individuals, defining and reinforcing shared values, and collectively clarifying which activities are within or not within their boundaries. That effect could be seen as the focusing of the workforce on clarified mission statements; managers and staff alike. The importance of the elicitation of unarticulated values-in-action into tangible values statements demonstrated in the WeValue approach also suggests that a distinction might need to be made in research generally between those and the more superficial values words used in everyday language without prior reflection. In fact, findings from previous studies might be negated in cases where individuals do not have shared values-in-action to build on but are trying to reconcile superficial values with no grounding in a context-specific reality. In such cases, values-based approaches might not only be non-useful but could easily lead to misunderstandings and even polarization of differences.

The success of the WeValue approach at triggering conceptualization and the production of indicators that are deemed valid by participants suggests it deserves further study, because a key feature of organizational values discourse is its portrayal of values as highly abstract. Values tend to be poorly conceptualized even at the individual level and are often below the level of full conscious awareness [43,67]. In the absence of collectively agreed definitions for specific value-labels such as "trust", "justice" or "integrity", individuals rely on their own tacit or explicit understandings of 
meaning. These understandings vary according to ethnicity, previous life experiences and current circumstances, and are highly context-dependent [68,69]. However, the concept of values is arguably useful within the context of business ethics as it provides a bridge between individuals, organizational culture and subsequent actions and behaviors [26] (p. 72).

Concerns about the abstract nature of values communication, and its perceived irrelevance to daily life, are raised elsewhere in the business management literature. Gruys et al. [70] (p. 833) lament that "too often the values of organizations show up on laminated cards or wall plaques, rarely heard or seen", while Lencioni's [71] (p. 113) damning verdict on corporate values statements is that the majority are "bland, toothless or just plain dishonest", with resulting destructive impacts on employee morale, client satisfaction and managerial credibility. Values transmitted implicitly through other channels such as rituals, drama, stories and symbolic constructions within an organization's culture may contradict those that are explicitly communicated in oral or written forms [72]. Even when there is a prominent and unambiguous values discourse within an organization, shared understanding of value meanings may be lacking. Focusing on values can thus backfire, as Cha and Edmondson [73] (p. 71) explain: "The inherently abstract or "fuzzy" nature of values creates the potential for multiple plausible interpretations of the values' appropriate meanings." They describe the problem of "values expansion": the tendency of employees to add new layers of meaning to the value-labels passed on to them by senior management. This may result in attributions of hypocrisy to leaders even as they continue to remain faithful to their original understandings of the value-labels, and often generates disenchantment-a "toxic" blend of frustration, anger, disappointment and loss of trust-among employees. Cha and Edmondson [73] speculate that such disenchantment might trigger increased absenteeism, impaired job performance, and detrimental effects on work attitudes and behaviors. Similarly, Lencioni [71] provides an actual example of a company in which incongruence between leaders' and employees' understandings of a single value-label led directly to the resignation of a senior executive.

Another important insight from the WeValue approach is contextualization. Early on in its development, it was clear that it needed to be steered away from being a rigid framework to one which could be localized and thus "owned" rather than seen as an external imposition. This successful localization of values-based indicators is only possible with the contribution provided by members of the organizations when they collectively reflect on their own actions - concretely contextualized in the workplace.

Business ethics concerns itself with the application of certain values that are related to deliberate decisions about what is or is not ethical in a given context. Thus, ethics and related organizational values are arguably more explicit and purposefully linked to practices and behaviors. In practice, this has been translated by the development of codes of ethics as mechanisms for ensuring such practices. However, codes and compliance-based approaches have been criticized and, akin to values discourses, remain vague and lack specificity [74]. Furthermore, what is ethical in a given organization is defined contextually and will not depend solely on a code [63]. In this context, there has been increasing interest in understanding ethics as practice, in other words that organizational ethics are constructed through a multiplicity or behaviors, decisions, inter-personal interactions "not only embed and enact ethics but also form the framework for their institutionalization, politicization and contestation" [75] (p. 94).

This way of understanding ethics may contribute to challenges faced by scholars looking at organizational values. Indeed, although values-based approaches are more effective, they do not necessarily generate tangible long-term outcomes [74]. The focus merely on the level of values discourse is limiting: related practices can also influence ethical organizational culture and specific behaviors such as willingness to report unethical behaviors.

The relatively limited evidence provided in this dataset suggests, provisionally, that the WeValue approach may contribute to the development of ethical cultures in organizations. Existing literature hints at possible ways to do this: Gruys et al. [70] suggest, for example, that a potential solution might be to obtain a measure of organizational values enactment by linking statements of espoused values directly to formal performance assessment systems. That measurement-based approach contrasts with Cha and Edmondson's more constructionist recommendation [73] (p. 75) of "thoughtful dialogue" 
between managers and employees about the meanings and practical implications of value-labels. In a recent paper, Warren et al. [74] argue that ethics training that examine practices related to ethical dilemmas in detail have more lasting effects that merely focusing on vague codes of ethics and organizational values. All of these studies are consistent with the impact findings reported here, which seem to go further and produce an embryonic framework to understand them.

\section{Conclusions}

The successful application of ethical values in organizations is of crucial importance for contributions of business and civil society to sustainable development. Business ethics scholars and practitioners have been at the forefront of such work in the past decades, and have recently identified outstanding challenges and gaps in research. These include problems of measurement, rigor, and meaningfulness to practitioners; CSR; decline of ethical behavior; and the institutionalization of ethics in businesses. Although this study was designed retrospectively as an exploration of unexpected outcomes of a research project in another area (sustainability indicators), the findings leave little doubt that the approach used in the WeValue evaluative interventions produced impacts that contribute significantly to current challenges in business ethics, starting with increased awareness and the institutionalization of values in the organizations, with related domino effects on ethics in discourse, communication and action.

The analysis provides clear indications of important areas of impact that are likely to be generalizable to other organizations using the WeValue approach, although dedicated designed studies should be carried out to confirm them. First, the approach may help participants to gain a shared understanding of "core shared values" in a more tangible way by collectively associating reasonably specific word-based phrases (proto-indicators), with local meaning obtained through consideration of concrete examples (values-in-action). This greatly raises awareness of local shared values in the context of the organization, which is a requirement to considerations of ethics. Second, the approach may enhance esteem and strengthen relationships at several levels, increasing understanding and acceptance of oneself, other individuals, the organization as a whole, and even wider human-environment systems. This raises the ethical consideration of the human aspects of co-working beyond work roles, and can be seen as the beginning of the embedding of ethics into relationships (with a knock on effect of reducing distance between managers and staff). Third, it may increase understanding and acceptance for various assessment methods, which become considered valid locally, thus building internal capacity for values-based performance assessment (which may be especially important in small non-profit organizations) and an expanding awareness of what is "measurable". Related to this is the reinforcement of the usefulness of values-based perspectives when measures of them are made tangible. Fourth, the use of the WeValue approach may catalyze internal transformation within the organization, both in terms of "values mainstreaming" (i.e., prioritizing specific ethical values in strategic planning, decision-making and performance assessment) and in other respects such as improving group dynamics and promoting positive behavior change without the need for authoritarian management. Finally, the approach can provide organizations with a new shared vocabulary for communicating previously intangible values-related goals and impacts to key external stakeholders, notably donors, policy-makers and prospective clients, and our data shows that the bridging of this significant communication gap can have immediate impacts of allowing stakeholders to work together more effectively towards shared understandings of goals.

Several caveats and limitations need stating. First, "the" WeValue evaluation intervention as used here was under development and carried out in the context of an ongoing research project, thus allowing for significant time and researcher involvement in the selection of indicators, development of assessments and follow-up. This also meant that elements within the intervention varied between the organizational contexts-both in materials used and facilitation approaches. The WeValue approach has since been further developed, and although the research team believe similar types of impacts would be seen regardless, they have no feel for the variations in strength of impacts that might change. Secondly, although the organizations differed in size, geographic location and nature (civil 
society/private sector), all were involved because of their connection, direct or indirect, to members of the project consortium, and thus were likely to be interested in values-related work. In future studies, organizations should be chosen more appropriately for an impact research question. Thirdly, the impacts were not predicted or planned for and thus no baselines, measures, or monitoring over time were carried out, and other types of impacts may have been missed completely. Finally, the study does not adequately account for long-term impacts, as the data used in the study was collected a maximum of 6 months after the intervention. All of these limitations need to be considered in any future studies. It is suggested that the early version of the WeValue approach is replaced by a further developed and systematized ones used in a wider diversity of organizations, using values-based indicators from a common reference list deemed suitable for the organizational context. (This can be found via an open search on the internet.). Future studies should include baselines and ongoing, long-term, non-participatory measures of the types of impacts reported here, as well as wider aspects. It is also suggested that researchers in business ethics and organizational studies be directly involved in such future work, to allow appropriate expert joint contributions.

Acknowledgments: The ESDinds Project (ESDinds: The Development of Indicators and Assessment Tools for Civil Society Organizations Promoting Education for Sustainable Development, Grant Agreement No. 212237) was funded by the European Union Seventh Framework Programme, FP7/2007-2013. The authors acknowledge the valuable input of the full ESDinds project consortium, and special thanks are due to the partner CSOs: the Alliance of Religions and Conservation (ARC), Earth Charter International (ECI), European Baha'i Business Forum (ebbf) and People's Theater. The follow-up study described in this paper was partly funded by the University of Brighton, and partly with resources from China National Thousand Talents Professorship funding for $\mathrm{MKH}$, including the costs of open access publication.

Author Contributions: Gemma Burford conceived and designed the exploratory impact study; Gemma Burford and Lee Stapleton analyzed the data; Marie K. Harder and Elona Hoover conceived and wrote up the links with academic business ethics as presented; Gemma Burford, Marie K. Harder and Elona Hoover wrote the paper.

Conflicts of Interest: Three of the authors (Gemma Burford, Elona Hoover and Marie K. Harder) were members of the research team that developed the original ESDinds indicators. However, the indicators are in the public domain and not subject to any form of intellectual property protection (www.esdinds.eu), and the authors do not gain any commercial benefit from their dissemination, use or application. The founding sponsors had no role in the design of the study; in the collection, analyses, or interpretation of data; in the writing of the manuscript, and in the decision to publish the results.

\section{Appendix A. Sample Indicators and Assessment Tools}

Table A1. A full list of the values-based indicators developed by one organization, DB during the WeValue evaluative intervention.

\begin{tabular}{lc}
\hline $\begin{array}{l}\text { Indicators Developed by One Organization, Which were Chosen for Developing Local } \\
\text { "Measures" for Self-Evaluation }\end{array}$ & Assessment Tools \\
\hline $\begin{array}{l}\text { Partners, member organizations and individuals do not feel that they have compromised } \\
\text { their beliefs by participating in the vision and activities of the organization/project. }\end{array}$ & Spatial Survey \\
\cline { 2 - 2 } Different points of view are heard and incorporated & Focus group \\
\hline $\begin{array}{l}\text { Degree to which members / partners feel that their individual identity and approach has } \\
\text { been respected. }\end{array}$ & Spatial Survey \\
\hline People are encouraged to reach their potential & Spatial Survey \\
\hline Everyone has his/her place in the team. & Spatial Survey \\
\hline Learning processes accommodate different learning styles & Spatial Survey \\
\hline $\begin{array}{l}\text { Individuals have a feeling of a unified work environment } \\
\text { Individuals learn together, share skills, abilities and information freely with one another } \\
\text { regardless of creed, color, ethnicity, gender }\end{array}$ & Spatial Survey \\
\hline Members are inclusive (talk to everyone and no one is left out) & Spatial Survey \\
\hline Group norms exist. People follow the group norms. & Spatial Survey \\
\hline Women believe they are valued & Spatial Survey \\
\hline
\end{tabular}


Table A1. Cont.

\begin{tabular}{|c|c|}
\hline $\begin{array}{l}\text { Indicators Developed by One Organization, Which were Chosen for Developing Local } \\
\text { "Measures" for Self-Evaluation }\end{array}$ & Assessment Tools \\
\hline Individuals have a feeling of harmony and pleasant work environment. & Spatial Survey \\
\hline Long term commitments to protect the environment are created and adhered to & Unobtrusive measures \\
\hline $\begin{array}{l}\text { Education is undertaken to raise awareness and capabilities for the organization to act } \\
\text { according to principles of environmental sustainability }\end{array}$ & Unobtrusive measures \\
\hline \multirow{3}{*}{$\begin{array}{l}\text { Quality of process and results of activities or projects aiming to achieve or promote } \\
\text { environmental sustainability }\end{array}$} & $\begin{array}{l}\text { Forum Theatre } \\
\text { Comprehension Test }\end{array}$ \\
\hline & Unobtrusive measures \\
\hline & $\begin{array}{l}\text { Key informant } \\
\text { unstructured interview }\end{array}$ \\
\hline $\begin{array}{l}\text { Activities initiated and completed in the conscious aim of contributing to a greater respect } \\
\text { for nature }\end{array}$ & Indirect Measures \\
\hline $\begin{array}{l}\text { Activities initiated and completed in the conscious aim of contributing to a greater } \\
\text { understanding and respect of how nature is organized (systems and cycles) }\end{array}$ & Indirect Measures \\
\hline $\begin{array}{l}\text { Activities initiated and completed in the conscious aim of contributing to a greater valuing } \\
\text { of the natural world as a source of personal fulfilment }\end{array}$ & Indirect Measures \\
\hline $\begin{array}{l}\text { Activities initiated and completed that share with others how to protect and restore the } \\
\text { Earth's health }\end{array}$ & Indirect Measures \\
\hline \multirow{3}{*}{ The project's activities/events have an emotional effect on participants } & Indirect measures \\
\hline & Word elicitation \\
\hline & $\begin{array}{l}\text { Spatial Survey Indirect } \\
\text { measures }\end{array}$ \\
\hline $\begin{array}{l}\text { This organization started with the two core values of Respect and Care for the Co } \\
\text { Collaboration in Diversity, from which they developed } 22 \text { indicators, and priori } \\
\text { development of local measures in their current self-evaluation. For more detail on the } \\
\text { Harder et al. [26]. }\end{array}$ & $\begin{array}{l}\text { nunity of Life, and } \\
\text { ed those above for } \\
\text { atial survey tool, see }\end{array}$ \\
\hline
\end{tabular}

\section{References and Notes}

1. McCool, S.; Stankey, G. Indicators of sustainability: Challenges and opportunities at the interface of science and policy. Environ. Manag. 2004, 33, 294-305. [CrossRef] [PubMed]

2. Vucetich, A.J.; Nelson, M.P. Sustainability: Virtuous or vulgar? BioScience 2010, 60, 539-544. [CrossRef]

3. Clugston, R. Ethical Framework for a Sustainable World: Earth Charter Plus 10 conference and follow up. J. Educ. Sustain. Dev. 2011, 5, 173-176. [CrossRef]

4. Hedlund-de Witt, A. The rising culture and worldview of contemporary spirituality: A sociological study of potentials and pitfalls for sustainable development. Ecol. Econ. 2011, 70, 1057-1065. [CrossRef]

5. Burford, G.; Hoover, E.; Velasco, I.; Janoušková, S.; Jimenez, A.; Piggot, G.; Podger, D.; Harder, M.K. Bringing the 'missing pillar' into Sustainable Development Goals: Towards intersubjective values-based indicators. Sustainability 2013, 5, 3035-3059. [CrossRef]

6. Dahl, A.L. Achievements and gaps in indicators for sustainability. Ecol. Indic. 2012, 17, 14-19. [CrossRef]

7. Littig, B.; Griessler, E. Social sustainability: A catchword between political pragmatism and social theory. Int. J. Sustain. Dev. 2005, 8, 65-79. [CrossRef]

8. Elliott, J.A. An Introduction to Sustainable Development; Routledge: London, UK, 2012.

9. Hawkes, J. The Fourth Pillar of Sustainability: Culture's Essential Role in Public Planning; Common Ground Publishing Pty Ltd in association with the Cultural Development Network: Victoria, Australia, 2001.

10. UNESCO. Culture in the Post-2015 Sustainable Development Agenda: Why Culture is Key to Sustainable Development. In Proceedings of the 2013 Hangzhou Congress on Culture and Development, Hangzhou, China, 14-17 May 2013.

11. De Leo, J. Quality Education for Sustainable Development: An Educator Handbook for Integrating Values, Knowledge, Skills and Quality Features of Education for Sustainable Development in Schooling; UNESCO APNIEVE Australia Publishing: Adelaide, Australia, 2012. 
12. Kagan, S. Art and sustainability: Connecting Patterns for a Culture of Complexity; Transcript Verlag: Bielefeld, Germany, 2011.

13. Woodley, E.; Crowley, E.; Dookie, C.; Carmen, E. Cultural Indicators of Indigenous Peoples' Food and Agro-Ecological Systems; Food and Agriculture Organization of the United Nations: Rome, Italy, 2006.

14. UN-PFII. Report of the Meeting on Indigenous Peoples and Indicators of Well-Being, Ottawa, 22-23 March 2006; United Nations Permanent Forum on Indigenous Issues: New York, NY, USA, 2006.

15. Nurse, K. Culture as the Fourth Pillar of Sustainable Development; Commonwealth Secretariat: London, UK, 2006.

16. Interreligious Statement. Towards Rio+20 and Beyond-A Turning Point in Earth's History; Southern African Faith Communities' Environment Institute: Kalk Bay, South Africa, 2012.

17. Pfahl, S. Institutional sustainability. Int. J. Sustain. Dev. 2005, 8, 80-96. [CrossRef]

18. Spangenberg, J.H.; Pfahl, S.; Deller, K. Towards indicators for institutional sustainability: Lessons from an analysis of Agenda 21. Ecol. Indic. 2002, 2, 61-77. [CrossRef]

19. Corcoran, P.B.; Vilela, M.; Roerink, A. The Earth Charter in Action: Toward a Sustainable Development; Royal Tropical Institute (KIT): Amsterdam, The Netherlands, 2005.

20. ECI Secretariat. Earth Charter Initiative Handbook; Earth Charter Initiative: San José, Costa Rica, 2010.

21. United Nations General Assembly. United Nations Millennium Declaration; United Nations General Assembly: New York, NY, USA, 2000.

22. Biermann, F. 'Earth system governance' as a crosscutting theme of global change research. Glob. Environ. Chang. 2007, 17, 326-337. [CrossRef]

23. Palmer, M.; Wagner, K. ValuesQuest: The Search for Values Which Will Make a World of Difference; The Club of Rome: Zurich, Switzerland, 2012.

24. Carroll, A.B. Ethical challenges for business in the new millennium: Corporate social responsibility and models of management morality. Bus. Ethics Q. 2000, 10, 33-42. [CrossRef]

25. Holland, D.; Albrecht, C. The worldwide academic field of business ethics: Scholars' perceptions of the most important issues. J. Bus. Ethics 2013, 117, 777-788. [CrossRef]

26. Von Groddeck, V. Rethinking the Role of Value Communication in Business Corporations from a Sociological Perspective-Why Organisations Need Value-Based Semantics to Cope with Societal and Organisational Fuzziness. J. Bus. Ethics 2011, 100, 69-84. [CrossRef]

27. Heugens, P.P.M.A.R.; Scherer, A.G. When organization theory met business ethics: Toward further symbioses. Bus. Ethics Q. 2010, 20, 643-672.

28. Robinson, J. Squaring the circle? Some thoughts on the idea of sustainable development. Ecol. Econ. 2004, 48, 369-384. [CrossRef]

29. Waas, T.; Hugé, J.; Verbruggen, A.; Wright, T. Sustainable development: A bird's eye view. Sustainability 2011, 3, 1637-1661. [CrossRef]

30. Pryshlakivsky, J.; Searcy, C. Sustainable development as a wicked problem. In Managing and Engineering in Complex Situations; Kovacic, S.F., Sousa-Poza, A., Eds.; Springer Netherlands: Dordrecht, The Netherlands, 2012; pp. 109-128.

31. Ioppolo, G.; Cucurachi, S.; Salomone, R.; Saija, G.; Shi, L. Sustainable local development and environmental governance: a strategic planning experience. Sustainability 2016, 8, 180. [CrossRef]

32. Burford, G.; Velasco, I.; Janoušková, S.; Zahradnik, M.; Hak, T.; Podgera, D.; Piggot, G.; Harder, M.K. Field trials of a novel toolkit for evaluating 'intangible' values-related dimensions of projects. Eval. Program Plan. 2013, 36, 1-14. [CrossRef] [PubMed]

33. Harder, M.K.; Velasco, I.; Burford, G.; Podger, D.; Janoušková, S.; Piggot, G.; Hooveret, E. Reconceptualizing 'efffectiveness' in environmental projects: Can we measure values-related achievements? J. Environ. Manag. 2014, 139, 120-134. [CrossRef] [PubMed]

34. Podger, D.; Velasco, I.; Luna, C.A.; Burford, G.; Harder, G. Can values be measured? Significant contributions from a small civil society organisation through action research evaluation. Action Res. 2013, 11, 8-30. [CrossRef]

35. Ribeiro, M.M.; Hoover, E.; Burford, G.; Buchebner, J.; Lindenthal, T. Values: A bridge between sustainability and institutional assessment-a case study from BOKU University. Int. J. Sustain. High. Educ. 2016, 17, 40-53. [CrossRef]

36. Reynolds, S.J. Moral attentiveness: Who pays attention to the moral aspects of life? J. Appl. Psychol. 2008, 93, 1027-1041. [CrossRef] [PubMed] 
37. McFerran, B.; Acquino, K.; Duffy, M. How personality and moral identity relate to individuals' ethical ideology. Bus. Ethics Q. 2010, 20, 35-56. [CrossRef]

38. Podger, D.; Hoover, E.; Burford, G.; Hak, T.; Harder, M.K. Revealing values in a complex environmental program: A scaling up of values-based indicators. J. Clean. Prod. 2015. [CrossRef]

39. Podger, D.; Piggot, G.; Zahradnik, M.; Janoušková, S.; Velasco, I.; Hak, T.; Dahl, A.; Jimenez, A.; Harder, M.K. The Earth Charter and the ESDinds initiative: Developing indicators and assessment tools for civil society organisations to examine the values dimensions of sustainability projects. J. Educ. Sustain. Dev. 2010, 4, 297-305. [CrossRef]

40. Cohen, L.; Manion, L.; Morrison, K. Research Methods in Education, 7th ed.; Routledge: Abingdon, UK, 2011.

41. ESDinds. ESDinds: The Development of Values-Based Indicators and Assessment Tools for Civil Society organizations Promoting Education for Sustainable Development. Deliverable 17: Final Project Report to European Commission Seventh Framework Programme (FP7/2007-2013). ESDinds Project Consortium led by University of Brighton: Brighton, UK, 2011. ESDinds Project Consortium led by University of Brighton: Brighton, UK, 2011.

42. Alvesson, M.; Sveningsson, S. Good visions, bad micro-management and ugly ambiguity: Contradictions of (non-)leadership in a knowledge-intensive organization. Organ. Stud. 2003, 24, 961-988. [CrossRef]

43. Agle, B.R.; Caldwell, C.B. Understanding research on values in business: A level of analysis framework. Bus. Soc. 1999, 38, 326-387. [CrossRef]

44. ESDinds, ESDinds working paper: Report of Field Visit to Organisation ' $\mathrm{Hv}^{\prime}$ for Testing of Set 1 Sustainable Development Indicators. 2010, University of Brighton: Brighton, UK.

45. ESDinds, Face-to-face interview with 'Maria' (pseudonym), project manager for organisation 'DB', in ESDinds working paper: Transcripts of anonymised semi-structured interviews with participants in field tests of Set 1 Sustainable Development Indicators (companion material to ESDinds Deliverable 11), G. Burford, Editor. 2010, University of Brighton: Brighton, UK.

46. ESDinds, Skype verbal interview with 'Rachel' (pseudonym), project officer of organisation 'JGSD', in ESDinds working paper: Transcripts of anonymised semi-structured interviews with participants in field tests of Set 1 Sustainable Development Indicators (companion material to ESDinds Deliverable 11), G. Burford, Editor. 2010, University of Brighton: Brighton, UK.

47. ESDinds, ESDinds working paper: Report of field visit to organisation 'JGSD' for testing of Set 1 Sustainable Development Indicators. 2010, University of Brighton: Brighton, UK.

48. ESDinds, ESDinds working paper: Report of field visit to organisation 'DB' for testing of Set 1 Sustainable Development Indicators. 2010, University of Brightons: Brighton, UK.

49. ESDinds, Skype verbal interview with 'Ingrid', project manager of organisation 'QU', in ESDinds working paper: Transcripts of anonymised semi-structured interviews with participants in field tests of Set 1 Sustainable Development Indicators (companion material to ESDinds Deliverable 11), G. Burford, Editor. 2010, University of Brighton: Brighton, UK.

50. ESDinds, Skype verbal interview with 'Rachel' (pseudonym), JMSD project officer, talking about TMSD field visit, in ESDinds working paper: Transcripts of anonymised semi-structured interviews with participants in field tests of Set 1 Sustainable Development Indicators (companion material to ESDinds Deliverable 11), G. Burford, Editor. 2010, University of Brighton: Brighton, UK.

51. ESDinds, Face-to-face interview with 'Stefan', assistant ESDinds researcher on TMSD field visit, in ESDinds working paper: Transcripts of anonymised semi-structured interviews with participants in field tests of Set 1 Sustainable Development Indicators (companion material to ESDinds Deliverable 11), G. Burford, Editor. 2010, University of Brighton: Brighton, UK.

52. ESDinds, Face-to-face interview with 'Carlos', lead ESDinds researcher for field visit to organisation 'DB', in ESDinds working paper: Transcripts of anonymised semi-structured interviews with participants in field tests of Set 1 Sustainable Development Indicators (companion material to ESDinds Deliverable 11), G. Burford, Editor. 2010, University of Brighton: Brighton, UK.

53. ESDinds, Face-to-face interview with 'Josef', director of organisation 'QU', in ESDinds working paper: Transcripts of anonymised semi-structured interviews with participants in field tests of Set 1 Sustainable Development Indicators (companion material to ESDinds Deliverable 11), G. Burford, Editor. 2010, University of Brighton: Brighton, UK. 
54. ESDinds, Face-to-face interview with 'Carlos' (pseudonym), lead ESDinds researcher for field visit to organisation 'TMSD', in ESDinds working paper: Transcripts of anonymised semi-structured interviews with participants in field tests of Set 1 Sustainable Development Indicators (companion material to ESDinds Deliverable 11), G. Burford, Editor. 2010, University of Brighton: Brighton, UK.

55. ESDinds, Skype text interview with 'Ibrahim' (pseudonym), project manager for organisation 'TMSD', in ESDinds working paper: Transcripts of anonymised semi-structured interviews with participants in field tests of Set 1 Sustainable Development Indicators (companion material to ESDinds Deliverable 11), G. Burford, Editor. 2010, University of Brighton: Brighton, UK.

56. Christofi, A.; Christofi, P.; Sisaye, S. Corporate sustainability: Historical development and reporting practices. Manag. Res. Rev. 2012, 35, 157-172. [CrossRef]

57. Du, S.; Bhattacharya, C.B.; Sen, S. Maximising business returns to corporate social responsibility (CSR): The role of CSR communication. Int. J. Manag. Rev. 2010, 12, 8-19. [CrossRef]

58. Foote, J.; Gaffney, N.; Evans, J.R. Corporate social responsibility: Implications for performance excellence. Total Qual. Manag. 2010, 21, 799-812. [CrossRef]

59. Kemaghan, K. Integrating Values into Public Service: The Values Statement as Centerpiece. Public Adm. Rev. 2003, 63, 711-719. [CrossRef]

60. Buchko, A.A. The effect of leadership on values-based management. Leadersh. Organ. Dev. J. 2007, $20,36-50$. [CrossRef]

61. Garcia, S.M.; Bazerman, M.H.; Kopelman, S.; Tor, A.; Milleret, D.T. The price of equality: Suboptimal resource allocations across social categories. Bus. Ethics Q. 2010, 20, 75-88. [CrossRef]

62. Artto, K.; Kulvika, I.; Poskelab, J.; Turkulainen, V. The integrative role of the project management office in the front end of innovation. Int. J. Proj. Manag. 2011, 29, 408-421. [CrossRef]

63. Christensen, T.; Lægreid, P. Ethics and Administrative Reforms. Public Manag. Rev. 2011, 13, $459-477$. [CrossRef]

64. Huhtala, M.; Feldt, T.; Lämsä, A.-M.; Mauno, S.; Kinnunen, U. Does the ethical culture of organisations promote managers' occupational well-being? Investigating indirect links via ethical strain. J. Bus. Ethics 2011, 101, 231-247.

65. Andrews, C.M.; Baker, T.; Hunt, T.G. Values and person-organization fit: Does moral intensity strengthen outcomes? Leadersh. Organ. Dev. J. 2011, 32, 5-19. [CrossRef]

66. Verquer, L.M.; Beehr, T.A.; Wagner, S.H. A meta-analysis of relations between person-organization fit and work attitudes. J. Vocat. Behav. 2003, 63, 473-489. [CrossRef]

67. Meglino, M.B.; Ravlin, E.C. Individual values in organizations: Concepts, controversies, and research. J. Manag. 1998, 24, 351-389. [CrossRef]

68. Brown, D.; Crace, R.K. Values in Life Role Choices and Outcomes: A Conceptual Model. Career Dev. Q. 1996, 44, 211-223. [CrossRef]

69. Peng, K.P.; Nisbett, R.E.; Wong, N.Y.C. Validity problems comparing values across cultures and possible solutions. Psychol. Methods 1997, 2, 329-344. [CrossRef]

70. Gruys, M.L.; Stewart, S.M.; Goodstein, J.; Wick, A. Values enactment in organizations: A multi-level examination. J. Manag. 2008, 34, 806-843. [CrossRef]

71. Lencioni, P.M. Make your values mean something. Harv. Bus. Rev. 2002, 80, 113-117. [PubMed]

72. Kirkhaug, R. The management of meaning-Conditions for perception of values in a hierarchical organization. J. Bus. Ethics 2009, 87, 317-324. [CrossRef]

73. Cha, E.S.; Edmondson, A.C. When values backfire: Leadership, attribution, and disenchantment in a values-driven organization. Leadersh. Q. 2006, 17, 57-78. [CrossRef]

74. Warren, E.D.; Gaspar, J.P.; Laufer, W.F. Is formal ethics training merely cosmetic? A study of ethics training and ethical organizational culture. Bus. Ethics Q. 2014, 24, 85-117. [CrossRef]

75. Clegg, S.; Kornberger, M.; Rhodes, C. Business Ethics as Practice. Br. J. Manag. 2007, 18, 107-122. [CrossRef]

(C) 2016 by the authors; licensee MDPI, Basel, Switzerland. This article is an open access article distributed under the terms and conditions of the Creative Commons Attribution (CC-BY) license (http://creativecommons.org/licenses/by/4.0/). 